\title{
EFEITOS DA ALTURA DO TOCO NO VOLUME COLHIDO EM UM PLANTIO DE Pinus taeda L.
}

\section{EFFECTS OF TOCO HEIGHT IN VOLUME COLLECTED IN A PLANT OF Pinus taeda L.}

\author{
Lucas Venícius Zanella', Geedre Adriano Borsoi ${ }^{2}$, Carla Talita Pertille ${ }^{3}$, Marcos Felipe Nicoletti $^{4}$ \\ 1, 2, 3, 4 Universidade do Estado de Santa Catarina, Lages, Santa Catarina, Brasil - \\ lucas_zanella@outlook.com,geedre.borsoi@udesc.br,mes.florestal@gmail.com \& \\ marcos.nicoletti@udesc.br
}

\begin{abstract}
RESUMO
Objetivou-se quantificar o desperdício que a operação de corte florestal com o harvester exerce nas receitas de um plantio de Pinus taeda L. localizado em Timbó Grande/SC. A partir de inventário florestal realizado pela empresa, elaborou-se uma tabela de distribuição de frequências, afim de obter o número de árvores cubadas por classe diamétrica. Foram cubadas 42 árvores pelo método de Smalian e ajustou-se o modelo de afilamento de Prodan. Foram mensurados 150 tocos remanescentes pós colheita, para determinar a altura média de corte do local. Foram elaborados dois cenários para estimar a quantidade de volume em $\mathrm{m}^{3}$ deixado a campo e seu respectivo valor em $\mathrm{R} \$$ $\mathrm{m}^{-3}$ nos tocos. O primeiro envolveu a altura de corte a $24,38 \mathrm{~cm}$ e foi designado como cenário atual. Já o segundo, foi chamado de desejado com altura de corte de $16 \mathrm{~cm}$. A altura de corte média de corte encontrada foi de $24,38 \mathrm{~cm}$, enquanto que a altura mínima possível foi de $16 \mathrm{~cm}$, gerando em média $8,4 \mathrm{~cm}$ de excesso na altura de corte. Para o cenário atual, o volume médio a ser colhido foi de $2,32 \mathrm{~m}^{3}$ árvore ${ }^{-1}$, com valor médio de $\mathrm{R} \$ 389,47$ por árvore, resultando em uma produtividade de $562,02 \mathrm{~m}^{3}$ ha- ${ }^{1}$ com receita de $\mathrm{R} \$$ ha- ${ }^{1} 94.652,57$. Já para o cenário desejado, a média do volume estimado foi de $2,34 \mathrm{~m}^{3}$ árvore ${ }^{-1}$, com valor médio de $\mathrm{R} \$ 392,34$ por árvore, com produtividade de $569,42 \mathrm{~m}^{3}$ ha-1 e renda bruta de $\mathrm{R} \$$ ha- $^{-1}$ 95.351,38.
\end{abstract}

PALAVRAS-CHAVE: Corte florestal, Perdas de produção, Produtividade.

\section{ABSTRACT}

The objective of this study was to quantify the waste that the forest cutting operation with the harvester exerts on the revenues of a plantation of Pinus taeda L. located in Timbó Grande / SC. From the forest inventory carried out by the company, a frequency distribution table was elaborated in order to obtain the number of trees cubed by diameter class. 42 trees were cubed by the Smalian method and the Prodan tapering model was adjusted. A total of 150 remaining post-harvest stumps were measured to determine the mean cut-off height of the site. Two scenarios were elaborated to estimate the amount of volume in $\mathrm{m}^{3}$ left in the field and its respective value in $\mathrm{R} \$ \mathrm{~m}^{-3}$ in the stumps. The first involved cutting height to $24.38 \mathrm{~cm}$ and was designated as the current scenario. The second one was called the desired one with a cutting height of $16 \mathrm{~cm}$. The average cutting height found was $24.38 \mathrm{~cm}$, while the minimum possible height was $16 \mathrm{~cm}$, generating on average $8.4 \mathrm{~cm}$ of excess at the cutting height. For the current scenario, the average volume was collected at $2.32 \mathrm{~m}^{3}$ tree- ${ }^{1}$, with an average value of $R \$ 389.47$ per tree, resulting in a productivity of $562.02 \mathrm{~m}^{3}$ ha- ${ }^{1}$ with revenue of $\mathrm{R} \$$ ha- $^{1} 94,652.57$. For the desired scenario, the mean free volume was $2.34 \mathrm{~m}^{3}$ tree- ${ }^{1}$, with an average value of $R \$ 392.34$ per tree, with a yield of $569.42 \mathrm{~m}^{3}$ ha- $^{-1}$ and income gross of $R \$$ ha- $^{-1}$ $95,351.38$.

KEYWORDS: Forest cutting, Production losses, Productivity. 


\section{INTRODUÇÃO}

No setor florestal, a colheita de madeira compreende uma das mais importantes atividades florestais juntamente com o transporte. Considerada como uma das últimas etapas do processo produtivo de um plantio florestal, a colheita de madeira é influenciada por diversos fatores como espécie florestal, idade do plantio, finalidade do produto e condições topográficas do terreno (SILVA et al., 2013). A representação econômica dessa atividade e sua alta participação nas despesas finais da madeira posta na indústria, pode representar mais de $50 \%$ dos custos totais da madeira posta na indústria (MACHADO et al., 2014).

A mecanização da colheita florestal no Brasil ocorreu com a abertura do mercado brasileiro a importação de máquinas e equipamentos florestais a partir da década de 1990 e se intensificou significativamente no decorrer dos anos seguintes (BRAMUCCI \& SEIXAS, 2002). As principais máquinas do setor florestal importadas no Brasil, para efetuar a colheita são os tratores florestais harvester, feller-buncher, skidder e forwarder (MACHADO, 2014). Além disso, a aplicação de cada máquina dependerá do tipo de floresta, do terreno e objetivo do produto (LIMA \& LEITE, 2014)

Grandes empresas florestais utilizam de máquinas de elevada tecnologia para realização do corte e extração florestal. Contudo, Lima \& Leite (2014) afirmam que existem lacunas no que diz respeito a utilização dessas máquinas relacionadas as condições operacionais, como o modelo e a potência das máquinas e devido as condições das florestas, como volume e declividade do terreno. Malinovski et al. (2014) também destacam as condições do plantio florestal, relevo, sistema de colheita e o próprio tipo da máquina como fatores que influenciam o desempenho das máquinas utilizadas na colheita florestal.

Serpe et al. (2018) apontam as perdas decorrentes da colheita florestal como um fator decisivo para a tomada de decisões no setor florestal. Tais perdas podem ser maiores ou menores de acordo com a qualidade do plantio e das operações associadas a colheita florestal. Além disso, o desempenho dos operadores das máquinas, como o harvester, provoca as perdas dentro da área florestal. Para melhorar o desempenho das máquinas e dos operadores, técnicas como o treinamento em simulador de realidade virtual estão sendo desenvolvidas (LOPES et al., 2008). Fiedler et al. (2013) sugerem que tais desperdícios evidenciam a necessidade de se realizar avaliações para determinação destas perdas em termos econômicos, com o intuito de gerar a maximização das receitas.
Diante disso, pesquisas que visam investigar quais variáveis que influenciam a produtividade de colheita de madeira em plantios florestais são de suma importância, causando a minimização dos custos e prejuízos e a melhoria da otimização operacional. Esses fatores podem ser identificados por meio de estudos com estimativas da produtividade, proporcionando recursos para a tomada de decisões no processo de produção (SIMÕES \& FENNER, 2010).

O excesso de altura de corte de abate insere-se nessa temática, por acarretar prejuízos na colheita florestal. Essa variável interfere em perdas volumétricas na floresta colhida, não se restringindo somente as toras dos sortimentos de maiores de diâmetro na ponta fina, mas a todas as classes de sortimentos da floresta. Isso se deve ao aumento da altura de corte de abate da árvore que irá reduzir o volume das toras provenientes. Além disso, a declividade da área também influencia na altura de corte de abate, pois em terrenos muito declivosos, será mais difícil obter cortes de abate baixos.

Entretanto, pesquisas dessa variável sobre o impacto no volume final e em valores financeiros são escassos na literatura. Sendo assim, esse estudo teve como objetivo determinar as perdas volumétricas de um plantio de Pinus taeda L. durante as operações de corte florestal com harvester por meio da avaliação e quantificação de cenários financeiros envolvendo diferentes alturas de toco.

\section{MATERIAL E MÉTODOS}

O estudo foi conduzido em um plantio de Pinus taeda L. localizado no munícipio de Timbó Grande/SC, com coordenadas Leste: 5.394.54 m e Norte: 7.050.120 m. A área apresenta clima do tipo $\mathrm{Cfb}$, classificado como mesotérmico úmido de acordo com Köppen, precipitação média anual de $1.608 \mathrm{~mm}$ com chuvas bem distribuídas ao longo do ano. A temperatura média anual é de $16,6^{\circ} \mathrm{C}$ e a umidade relativa do ar média é de 78,2\% (ALVARES et al., 2013).

O plantio de Pinus taeda L. possui área de efetivo plantio de 79,4 hectares, espaçamento de 2,0 $\mathrm{m} \times 2,5 \mathrm{~m}$, com primeiro desbaste realizado aos 8 anos, segundo aos 12 anos, terceiro aos 16 anos e quarto aos 20 anos. A idade desse plantio é de 25 anos. O regime de corte empregado foi de corte raso. O sistema de colheita empregado foi o de toras curtas (cut to lenght), no qual o harvester é responsável pela operação de corte e o forwarder pelo baldeio.

É importante ressaltar que os tocos foram mensurados após o corte com o harvester e após o baldeio com o 
forwarder. Contudo, o forwarder não passou por todo o terreno onde estavam os tocos, pois o harvester agrupa as toras cortadas de cada sortimento em pequenos estaleiros ao longo do talhão, reduzindo o deslocamento do forwarder.

Os sortimentos foram classificados de acordo com a Tabela 1.

Tabela 1. Sortimentos comerciais utilizados para o plantio de Pinus taeda L.

\begin{tabular}{ccc}
\hline Diâmetro na ponta fina $(\mathbf{c m})$ & $\begin{array}{c}\text { Comprimento } \\
\text { das toras }\end{array}$ & $\mathbf{R} \mathbf{\$} / \mathbf{m}^{\mathbf{3}}$ \\
\hline$>35$ & 3,07 & 205,00 \\
25 a 34 & 3,07 & 135,00 \\
16 a 24 & 2,10 & 86,00 \\
8 a 15 & 2,10 & 60,00 \\
$<8$ & 2,40 & 57,00 \\
\hline
\end{tabular}

Em que: >35: toras com diâmetro mínimo na ponta fina de $35 \mathrm{~cm}$; 25 a 34: toras com diâmetro na ponta fina entre $25 \mathrm{~cm}$ e 34,99 cm; 16 a 24: toras com diâmetro na ponta fina entre 16 e 24,99 $\mathrm{cm} ; 8$ a 15: toras com diâmetro na ponta fina entre $8 \mathrm{~cm}$ e 15,99 $\mathrm{cm} ;<8$ : toras com diâmetro $<8 \mathrm{~cm}$.

A partir de dados de inventário florestal pré-corte raso do plantio, foi elaborada uma tabela de distribuição de frequências com seis classes para definir o procedimento de cubagem de rigorosa das árvores. Assim, foram cubadas 7 árvores pelo método de Smalian em cada classe, totalizando 42 árvores. Em cada árvore foram medidos os diâmetros nos seguintes comprimentos: 0,3 m;0,5 m; 0,9 m; 1,3 m; 2,3 m; 3,3 m; 4,3 m, e 5,3 m, a partir de 5,3 m de comprimento a cada $2 \mathrm{~m}$ até o final do fuste, sendo também medido a altura total. Também foram coletados os respectivos comprimentos dos diâmetros comerciais, de $8 \mathrm{~cm}, 16 \mathrm{~cm}, 25 \mathrm{~cm}$ e $35 \mathrm{~cm}$; utilizados para classificação das toras na ponta fina. Com tais dados, foi ajustado o modelo de Prodan (taper) (Equação 1) afim de estimar os diâmetros de interesse nas árvores cubadas.

$$
\begin{gathered}
\left(\frac{d i}{d a p}\right)=\beta 0+\beta 1 *\left(\frac{h i}{h}\right)+\beta 2 *\left(\frac{h i}{h}\right)^{2}+\beta 3 *\left(\frac{h i}{h}\right)^{3} \\
+\beta 4 *\left(\frac{h i}{h}\right)^{4}+\beta 5 *\left(\frac{h i}{h}\right)^{5}
\end{gathered}
$$

Em que: di = diâmetro mensurado a i-ésima altura da árvore em centímetros; dap = diâmetro da árvore à 1,3m de altura em centímetros; hi = altura referente ao diâmetro di em metros; e $\mathrm{h}=$ altura total da árvore em metros.

A altura mínima de corte (Figura 1) foi medida no cabeçote do harvester, sendo a distância entre o sabre de corte e a fração inferior do cabeçote. A altura obtida foi de $16 \mathrm{~cm}$.

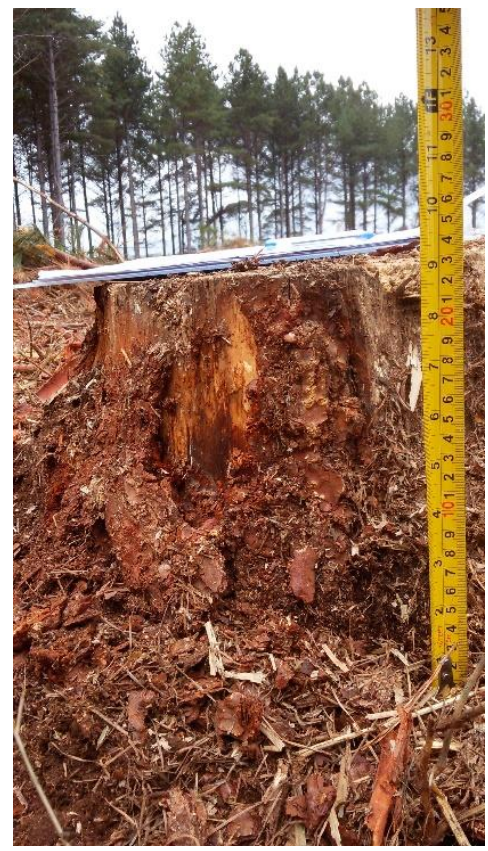

Figura 1. Medição da altura mínima de corte de abate.

Já a altura média de corte foi determinada a partir da coleta das alturas de corte de 150 tocos após operação de corte, com duas medidas de altura em lados opostos de cada toco. Essa avaliação foi realizada apenas nos locais onde já havia sido realizada a colheita, em uma subdivisão do talhão, sem a alocação das parcelas. O tipo de solo predominante na área compreende o Cambissolo Álico com relevo ondulado a forte ondulado. A área apresentou declividade entre 8 a $20 \%$, classificada como ondulada de acordo com Embrapa (2013).

Foram elaborados dois cenários para estimar a quantidade de volume em $\mathrm{m}^{3}$ deixado a campo e seu respectivo valor em $\mathrm{R} \$ \mathrm{~m}^{-3}$ nos tocos. 0 primeiro envolveu a altura de toco a $24,38 \mathrm{~cm}$ e foi designado como cenário atual. Já o segundo, foi chamado de desejado com altura de toco de $16 \mathrm{~cm}$. Para tal comparação, foram calculados os valores médios ( $R \$$ ) dos tocos e para cada tora considerando o sortimento.

Em cada cenário foram simulados os diâmetros nas pontas finas das toras para obter a quantidade de toras em média por sortimento, bem como o volume estimado em cada classe de sortimento e sua respectiva porcentagem. Além disso, foi estimado o volume não utilizado em tocos remanescentes a partir do valor médio de madeira em $\mathrm{m}^{3}$ calculado para a seção das árvores entre a altura de corte dos dois cenários. Por fim, multiplicou-se os volumes das 
árvores pelo valor do sortimento correspondente a classificação da tora pela ponta fina obtendo-se os volumes não utilizados por árvore.

Por fim, os dados foram analisados em dois tratamentos: o cenário atual e o desejado, por meio do volume de cada sortimento. Assim, os dados foram submetidos ao teste de normalidade de KolmogorovSmirnov e de homogeneidade de variâncias de Bartlett, ambos com $5 \%$ de significância. Em seguida, aplicou-se o teste $t$ para confrontar as diferentes situações com nível de $5 \%$ de significância. As análises foram realizadas no software R versão 3.4.1 (R CORE TEAM, 2018).

\section{RESULTADOS E DISCUSSÃO}

As características das variáveis dendrométricas para o plantio de Pinus taeda L. foram: DAP médio: $44,3 \mathrm{~cm}$; diâmetro da árvore de área basal média: $44,6 \mathrm{~cm}$; altura média total das árvores: $32,6 \mathrm{~m}$; altura dominante segundo o conceito de Assman (1970): 33,9 cm; número de árvores por hectare: 243; área basal por hectare: $37,9 \mathrm{~m}^{2}$; erro de amostraram absoluto do inventário: $70,5 \mathrm{~m}^{3} / \mathrm{ha}$; erro de amostragem relativo do inventário florestal: $12,7 \%$.

$\mathrm{O}$ ajuste do modelo de Prodan (Equação 2) estimou os diâmetros nas árvores cubadas com coeficiente de determinação ajustado de 0,9770 e erro padrão da estimativa de $7,0 \%$.

$$
d i=D_{A P} * \sqrt{\begin{array}{c}
1,14961-3,45838 *\left(\frac{h i}{h}\right)+14,9502 *\left(\frac{h i}{h}\right)^{2} \\
-31,85148 *\left(\frac{h i}{h}\right)^{3}+29,12700 *\left(\frac{h i}{h}\right)^{4}- \\
9,95861 *\left(\frac{h i}{h}\right)^{5}
\end{array}}
$$

Com a mensuração de 150 tocos na área de colheita florestal, a média de altura de toco foi de $24,38 \mathrm{~cm}$, sendo que nenhum apresentou altura média inferior a $10 \mathrm{~cm}$, com $63,3 \%$ dos tocos com alturas entre $20,1 \mathrm{~cm}$ a $30 \mathrm{~cm}$, e apenas 2,7\% dos tocos acima de $40 \mathrm{~cm}$.

Em ambos os cenários, os diâmetros médios na ponta fina das toras indicaram que, em média, as árvores forneceram cerca de 3 toras no sortimento $35 \mathrm{~cm}$ mínimos de diâmetro na ponta fina; 3 toras no sortimento de $25 \mathrm{~cm}$ a $35 \mathrm{~cm}$ na ponta fina; 2 toras no sortimento de 16 a $25 \mathrm{~cm}$ na ponta fina; 2 toras de 8 a $15 \mathrm{~cm}$ na ponta fina e um torete com no máximo $8 \mathrm{~cm}$ na ponta fina, sendo este material de descarte denominado resíduo ou ainda aproveitável, dependendo do mercado.

O cenário desejado, apresentou situação com melhor aproveitamento para a colheita mecanizada na floresta, com altura de corte em $16 \mathrm{~cm}$. Algumas condições foram importantes na determinação dessa altura, como a declividade da área que pode ser considerada ondulada

Nessa altura, os diâmetros médios na ponta fina das toras apresentaram comportamento semelhante ao cenário anterior para o número de toras por sortimento.

No cenário atual o sortimento de $>35 \mathrm{~cm}$ representou $54,8 \%$ da árvore, enquanto que 25 a $35 \mathrm{~cm}$ representou $34,1 \%$, de 16 a $25 \mathrm{~cm} \mathrm{7,6 \% ,} 8$ a $16 \mathrm{~cm} \mathrm{3,4 \%} \mathrm{e} \mathrm{os} \mathrm{resíduos}$ $0,2 \%$. Nos dois primeiros sortimentos com maior valor agregado, tem-se cerca de 729 toras ha-1 para cada um dos sortimentos já mencionados. Para os sortimentos 16 a $25 \mathrm{~cm}$ e 8 a $15 \mathrm{~cm}$ foram obtidas 486 toras ha-1 cada, no sortimento com no máximo $8 \mathrm{~cm}$ na ponta fina 243 toretes ha ${ }^{-1}$ por hectare. Para todos os sortimentos, estimou-se 2.673 toras por hectare.

A estimativa das perdas volumétricas e monetárias por árvore, por hectare e para a área total considerando o volume não utilizado nos tocos remanescentes indicou que, das 243 árvores por hectare, a quantidade estimada de madeira não aproveitada é de 4,09 $\mathrm{m}^{3} \mathrm{ha}^{-1}$, gerando uma perda de $\mathrm{R} \$ \mathrm{ha}^{-1} 838,85$; sendo para a área total de 79,4 ha, uma perda significativa de $324,9 \mathrm{~m}^{3}$, com perda expressiva de $R \$ 66.604,79$, que representa a estimativa de perda para a área total do talhão.

Para o volume não utilizado por árvore, de acordo com o valor do sortimento e volume da tora, notou-se que ocorreu um decréscimo nos valores em $\mathrm{R} \$ \mathrm{~m}^{-3}$, conforme a diminuição dos volumes. Isso causa uma diferença de 8,4 $\mathrm{cm}$ nas alturas de tocos, refletindo em perdas em volume de madeira e recursos financeiros por toras dentro de cada sortimento, sendo que apenas na primeira tora essa perda foi de $R \$ \mathrm{~m}^{-3} 1,36$.

$\mathrm{Na}$ Tabela 2 é possível visualizar as receitas e nas Tabelas 3 e 4 resultados por sortimento e as respectivas perdas para o cenário atual para o cenário desejado:

Tabela 2. Receitas obtidas para cada cenário analisado em um plantio de Pinus taeda L.

\begin{tabular}{ccccccc}
\hline $\mathbf{R}$ & $\mathbf{1}$ & $\mathbf{2}$ & $\mathbf{3}$ & $\mathbf{4}$ & $\mathbf{5}$ & Total \\
\hline $\mathrm{RA}$ & 261,21 & 106,89 & 19,32 & 1,81 & 0,23 & 389,47 \\
$\mathrm{RD}$ & 263,16 & 107,48 & 19,60 & 1,86 & 0,24 & 392,34 \\
\hline
\end{tabular}

Em que: R: Receita; RA: Receita Atual em R\$ árvore ${ }^{-1}$; RD: Receita desejada em $\mathrm{R} \$$ árvore-1, 1: sortimento de toras com diâmetro na ponta fina (>35 cm); 2: sortimento de toras com diâmetro na ponta fina entre $25 \mathrm{~cm}$ e $34,99 \mathrm{~cm}$; 3 : sortimento de toras com diâmetro na ponta fina entre 16 e $25 \mathrm{~cm}$; 4: sortimento de toras com diâmetro na ponta fina entre $8 \mathrm{~cm}$ e $15 \mathrm{~cm}$; 5 : sortimento de toras com diâmetro $<8 \mathrm{~cm}$. 
Tabela 3. Perdas nos sortimentos em $\mathrm{m}^{3}$ para os cenários avaliados em um plantio de Pinus taeda $\mathrm{L}$.

\begin{tabular}{ccccccc}
\hline $\mathbf{P}$ & $\mathbf{1}$ & $\mathbf{2}$ & $\mathbf{3}$ & $\mathbf{4}$ & $\mathbf{5}$ & Total \\
\hline P1 & 0,0095 & 0,0043 & 0,0033 & 0,0008 & 0,0002 & 0,02 \\
P2 & 2,31 & 1,05 & 0,79 & 0,20 & 0,04 & 4,40 \\
P3 & 183,7 & 83,7 & 62,9 & 15,5 & 3,3 & 349,10 \\
\hline
\end{tabular}

Em que: P: Perdas; P1: Perdas em $\mathrm{m}^{3}$ árvore ${ }^{-1}$ estimadas no cenário atual dentro de cada sortimento; $\mathrm{P} 2$ : $\left(\mathrm{m}^{3}\right.$.ha): estimativa de perdas por hectare em $\mathrm{m}^{3}$ dentro de cada sortimento no cenário atual; P3: perdas para a área total $\mathrm{em}^{3}$; 1 : sortimento de toras com diâmetro na ponta fina $(>35 \mathrm{~cm}) ; 2$ : sortimento de toras com diâmetro na ponta fina entre $25 \mathrm{~cm}$ e $34,99 \mathrm{~cm} ; 3$ : sortimento de toras com diâmetro na ponta fina entre 16 e $25 \mathrm{~cm}$; 4: sortimento de toras com diâmetro na ponta fina entre $8 \mathrm{~cm}$ e $15 \mathrm{~cm}$; 5: sortimento de toras com diâmetro $<8 \mathrm{~cm}$.

Tabela 4. Perdas nos sortimentos em $\mathrm{R} \$$ para os cenários avaliados em um plantio de Pinus taeda $\mathrm{L}$.

\begin{tabular}{ccccccc}
\hline S & $\mathbf{1}$ & $\mathbf{2}$ & $\mathbf{3}$ & $\mathbf{4}$ & $\mathbf{5}$ & Total \\
\hline P1 & 1,95 & 0,59 & 0,28 & 0,05 & 0,01 & 2,88 \\
P2 & 474,26 & 142,30 & 68,17 & 11,70 & 2,37 & 698,81 \\
P3 & $36.656,24$ & $11.298,75$ & $5.413,04$ & 929,17 & 188,02 & $55.485,2$ \\
\hline
\end{tabular}

Em que: $\mathrm{P} 1:$ perdas monetárias no cenário atual ( $\mathrm{R} \$ / \mathrm{m}^{3} /$ árvore); $\mathrm{P} 2$ : perdas monetárias por hectare para cada sortimento no cenário atual; P3: perdas para a área total em R\$; 1: sortimento de toras com diâmetro na ponta fina $(>35 \mathrm{~cm})$; 2 : sortimento de toras com diâmetro na ponta fina entre $25 \mathrm{~cm}$ e $34,99 \mathrm{~cm}$; 3 : sortimento de toras com diâmetro na ponta fina entre 16 e $25 \mathrm{~cm}$; 4: sortimento de toras com diâmetro na ponta fina entre $8 \mathrm{~cm}$ e $15 \mathrm{~cm}$; 5: sortimento de toras com diâmetro $<8 \mathrm{~cm}$.

Dessa forma, com o cenário atual, obteve-se um ganho por árvore de $R \$ 261,21$ para o sortimento de $35 \mathrm{~cm}$ na ponta fina; $R \$ 106,89$ no sortimento de 25 a $34,9 \mathrm{~cm}$ na ponta fina; $R \$ 19,32$ no sortimento de 16 a $24,9 \mathrm{~cm}$ na ponta fina; $R \$ 1,81$ no sortimento de 8 a $15,9 \mathrm{~cm}$ na ponta fina. Além disso, ainda cerca de $R \$ 0,23$ na classificação para toras com diâmetro na ponta fina menor que $8 \mathrm{~cm}$ puderam ser obtidos, totalizando $\mathrm{R} \$ 389,47$ árvore- ${ }^{1}$. Já para o cenário desejado, estimou-se um ganho de $\mathrm{R} \$$ 392,34 árvore- $^{1}$. Portanto, o excesso de $8,37 \mathrm{~cm}$ de altura de corte acarretou uma perda média de $\mathrm{R} \$ 2,88$ por árvore.

Os valores expressos nas Tabelas 3 e 4 mostram que devido à altura de corte excessiva, por hectare foram perdidos cerca de $4,4 \mathrm{~m}^{3}$ de madeira nos sortimentos, deixando de arrecadar cerca de $\mathrm{R} \$ 698,81 \mathrm{ha}^{-1}$. Para a área total de $79,4 \mathrm{ha}$, foram perdidos $349,11 \mathrm{~m}^{3}$ de madeira, o que em valores monetários representa $\mathrm{R} \$ 55.485,21$. A Figura 2 ilustra os valores médios por árvore dentro de cada sortimento, apresentados na Tabela 2.

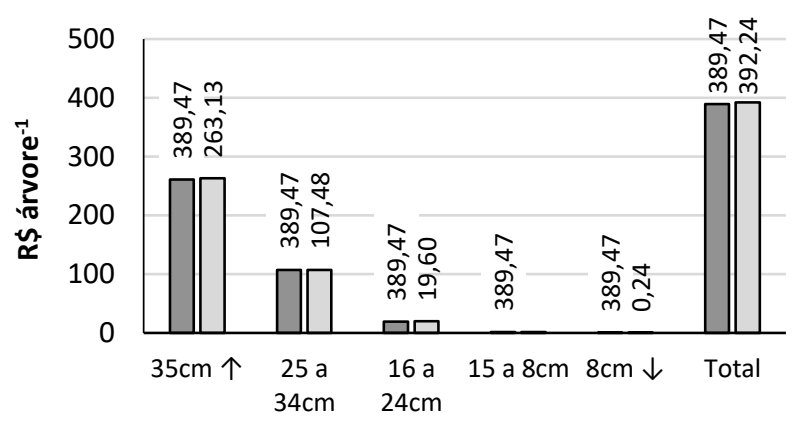

Sortimentos comerciais $(\mathrm{cm})$

$\square$ Valor médio atual Cenário 1 (R\$̦/árvore) $\square$ Valor desejado Cenário 2 (R\$̦/árvore)

Figura 2. Receitas por sortimento em diferentes cenários avaliados para um plantio de Pinus taeda L.

A Figura 3 ilustra os valores monetários que não foram arrecadados nos sortimentos por hectare apresentados na Tabela 1, na qual destaca-se os valores de $\mathrm{R} \$ \mathrm{ha}^{-1} 474,26$ no sortimento de $35 \mathrm{~cm}$ mínimo na ponta fina e $\mathrm{R} \$ \mathrm{ha}^{-1}$ 142,30 para o sortimento de toras com diâmetros de $25 \mathrm{~cm}$ a $34 \mathrm{~cm}$, sendo as classes com maiores valores agregados.

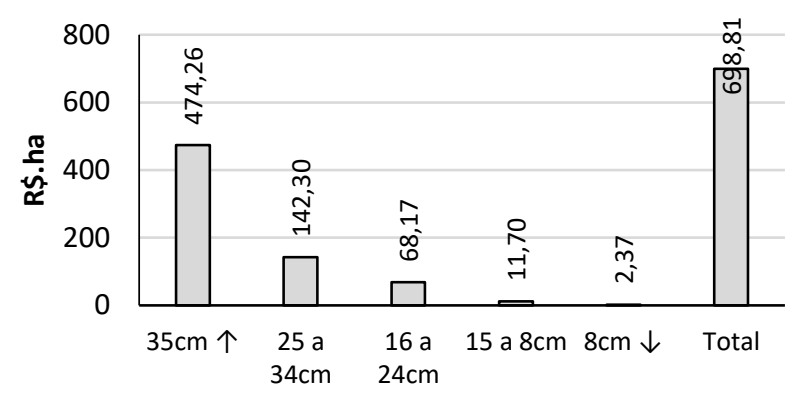

Sortimentos comerciais $(\mathrm{cm})$

Figura 3. Perdas monetárias estimadas por hectare dos sortimentos considerados para um plantio de Pinus taeda L.

A Figura 4 demonstra os valores perdas nos sortimentos para a área total na também citados nas Tabelas 3 e 4.

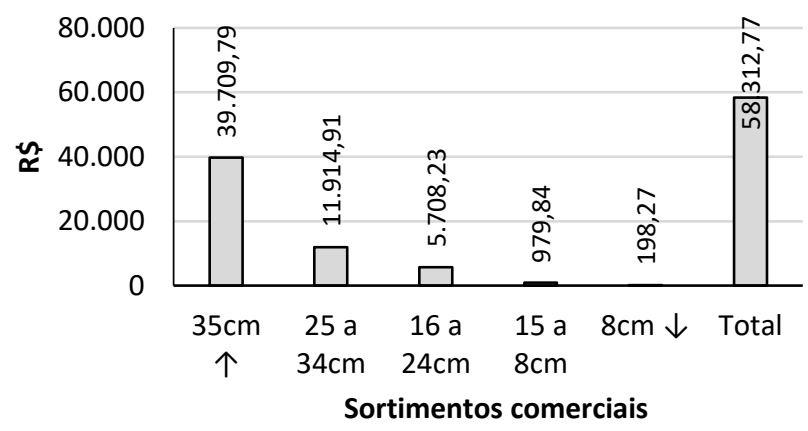

Figura 4. Perdas monetárias por sortimento estimadas na área total de um plantio de Pinus taeda $\mathrm{L}$. 
Pela produtividade atual na área, demonstrada pelo cenário atual, nota-se que para o plantio de 25 anos de idade, foi obtido em média $2,32 \mathrm{~m}^{3}$ árvore $^{-1}$, com valor médio de $\mathrm{R} \$ 389,47$ por árvore, com $562,02 \mathrm{~m}^{3} \mathrm{ha}^{-1}$ ou ainda em valores monetários $\mathrm{R} \$ \mathrm{ha}^{-1} 94.652,57$. O cenário desejado, por sua vez, apresentou $2,34 \mathrm{~m}^{3}$ árvore $^{-1}$ de volume médio a ser colhido, com valor médio de $\mathrm{R} \$ 392,34$ por árvore, representando $569,42 \mathrm{~m}^{3} \mathrm{ha}^{-1}$ e renda bruta de $\mathrm{R} \$ \mathrm{ha}^{-1}$ 95.351,38.

Diante disso, foi possível perceber que a altura de corte excedente em $8,37 \mathrm{~cm}$ nos sortimentos comerciais, acarretou em $0,0181 \mathrm{~m}^{3}$ árvore ${ }^{-1}$ de volume por árvore que não foram colhidos, ocasionado uma perda em valores monetários de $\mathrm{R} \$ 2,88$ por árvore. A diferença entre a arrecadação nos cenários gerados chegou a $\mathrm{R} \$ 698,81$ ha $^{-1}$ (Tabela 5).

Tabela 5. Comparação dos cenários avaliados quanto ao impacto da colheita florestal em um plantio de Pinus taeda $\mathrm{L}$.

\begin{tabular}{cccc}
\hline \multirow{2}{*}{ Variáveis } & \multicolumn{2}{c}{ Cenário } & \multirow{2}{*}{ Variação } \\
\cline { 2 - 3 } & Atual & Desejado & \\
\hline $\begin{array}{c}\text { Produtividade } \\
\text { Árvore-1 }\left(\mathrm{m}^{3}\right)\end{array}$ & 2,325 & 2,343 & 0,0181 \\
$\begin{array}{c}\text { Arrecadação } \\
\left(\mathrm{R} \$ \text { árvore- }^{-1}\right)\end{array}$ & $\mathrm{R} \$ 389,47$ & $\mathrm{R} \$ 392,34$ & $\mathrm{R} \$ 2,88$ \\
$\begin{array}{c}\text { Produtividade } \\
\left.\text { ( }^{3} \text { ha }^{-1}\right)\end{array}$ & 565,02 & 569,42 & 4,40 \\
$\begin{array}{c}\text { Arrecadação } \\
\left(\mathrm{R} \$ \text { ha }^{-1}\right)\end{array}$ & $\mathrm{R} \$ 94.652,57$ & $\mathrm{R} \$ 95.351,38$ & $\mathrm{R} \$ 698,81$ \\
\hline
\end{tabular}

A avaliação da perda de volume por árvore (Tabela 6) demonstrou que as perdas nos tocos e sortimentos totalizaram em $8,49 \mathrm{~m}^{3}$ ha-1 de volume médio não aproveitado. Isso causou perda de $\mathrm{R} \$ 1.537,66$ por hectare e $674,01 \mathrm{~m}^{3}$ para a área total, com consideráveis $R \$$ $122.090,00$. Contudo, apesar do valor estimado para a perda monetária na área total ser expressivo, tal resultado representa apenas $1,62 \%$ da renda bruta ( $R \$$ ) esperada para a área.

De acordo com as análises estatísticas, os dados seguem distribuição normal e as variâncias são homogêneas. Pelo teste $t$, o tabelado foi de 1,658 , enquanto

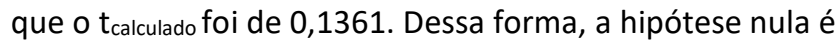
rejeitada, demonstrando que não houve diferença significativa entre os tratamentos (cenário atual e cenário desejado).

O impacto da colheita florestal também foi abordado em diversas pesquisas. $\mathrm{O}$ diagnóstico das quantidades de madeira desperdiçadas na área dos talhões após a extração em povoamentos florestais para celulose e madeira serrada foi realizado por Ferreira et al. (1995), no qual as perdas econômicas contabilizaram $\mathrm{R} \$$ 659.545,60.

Tabela 6. Perdas volumétricas e monetárias totais em um plantio de Pinus taeda L.

\begin{tabular}{cccc}
\hline Variável & Tocos & Sortimentos & $\begin{array}{c}\text { Tocos e } \\
\text { sortimentos }\end{array}$ \\
\hline $\begin{array}{c}\text { V. médio } \\
\left(\mathrm{m}^{3} \text { ha }^{-1}\right)\end{array}$ & 4,09 & 4,40 & 8,49 \\
$\begin{array}{c}\text { V. médio } \\
\left(\mathrm{m}^{3}\right)\end{array}$ & 324,9 & 349,1 & 674,0 \\
$\begin{array}{c}\text { Valor } \\
\left(\mathrm{R} \$ \mathrm{ha}^{-1}\right)\end{array}$ & $\mathrm{R} \$ 838,85$ & $\mathrm{R} \$ 698,81$ & $\mathrm{R} \$ 1.537,66$ \\
$\begin{array}{c}\text { Valor }- \\
\text { AT }(\mathrm{R} \$)\end{array}$ & $\mathrm{R} \$ 66.604,79$ & $\mathrm{R} \$ 55.485,21$ & $\mathrm{R} \$ 122.090,00$ \\
\hline
\end{tabular}

Em que: $\mathrm{V}$. médio = volume médio $\left(\mathrm{m}^{3}\right) ;$ e AT = Área total.

O impacto da colheita florestal também foi abordado em diversas pesquisas. O diagnóstico das quantidades de madeira desperdiçadas na área dos talhões após a extração em povoamentos florestais para celulose e madeira serrada foi realizado por Ferreira et al. (1995), no qual as perdas econômicas contabilizaram $\mathrm{R} \$$ 659.545,60.

A influência do comprimento e otimização de toras em Pinus pinaster foi avaliada por Campos \& Tavares (2010). Os autores concluíram que após a colheita, houve redução nos sortimentos.

As perdas em termos monetários, assim como nessa pesquisa, também foram expressivas no estudo de Fidler et al. (2013). Tais perdas representaram entre 14,92 a $21,82 \mathrm{R} \$$ ha- $^{1}$ do volume de volume de madeira retido nas cepas em povoamentos de Eucalyptus spp.

Outro fator que pode ter influenciado na quantidade de madeira desperdiçada está relacionado com o sistema de colheita. Nesse trabalho, o sistema empregado foi o de toras curtas (cut to lenght), contudo, na pesquisa de Stroher et al. (2014), o sistema de árvores inteiras (full tree) gerou os maiores desperdícios de madeira das cepas das árvores de Pinus taeda L. cut to lenght.

Um fator que interfere nas operações de colheita é a declividade do terreno. Por isso, Reboleto et al. (2016) avaliaram a qualidade da colheita florestal semimecanizada em plantio de eucalipto, em quatro declividades $\left(0^{\circ}, 10^{\circ}, 20^{\circ}\right.$ e $\left.30^{\circ}\right)$ previamente estabelecidas conforme a configuração do terreno. Os dados encontrados confirmaram a interferência da declividade na altura das cepas. A declividade de $30^{\circ}$ apresentou diferenças significativas ao nível de $5 \%$ pelo teste Tukey em relação as demais declividades, evidenciando a necessidade de melhorias na qualidade do corte 
semimecanizado, por apresentar valores acima do recomendado.

A declividade do terreno, não foi mensurada nesta pesquisa (apenas avaliada pela classificação da Embrapa (2013), é uma variável que pode interferir na altura de corte de abate, como comprova a pesquisa de Reboleto et al. (2016).

Os resultados evidenciaram que houve desperdício de madeira do povoamento avaliado, contudo, não foram avaliadas estratégias de reaproveitamento desse material. Nanvonamuquitxo et al. (2017) avaliaram a viabilidade do reaproveitamento de desperdício de madeira no processo de exploração florestal na concessão florestal de uma empresa centrada na Província da Zambézia em Moçambique e determinaram o rendimento volumétrico por unidade de árvore abatida pela empresa.

Os resultados mostraram que as peças de madeira desperdiçadas pela indústria durante processo de extração de toras apresentam tamanhos que permitem o seu reaproveitamento. As perdas de madeira foram consideradas altas $(55,68 \%)$ em relação a madeira aproveitada pela indústria (44,32\%), o que indica a necessidade de serem tomadas medidas corretivas para redução e/ou reaproveitamento de tais perdas.

As perdas volumétricas e monetárias para os tocos foram de $342,62 \mathrm{~m}^{3}$ e $838,85 \mathrm{R} \$ \mathrm{ha}^{-1}$, enquanto que para plantios de Pinus elliottii Engelm e Pinus taeda L. avaliados por Serpe et al. (2018), as perdas corresponderam a $11,92 \%$ do volume de madeira relacionado ao toco de $1,35 \%$ do volume total. O volume retido no toco acima do padrão resultou em $\mathrm{R} \$ 30,60 \mathrm{ha}^{-1}$ perdidos e a perda por quebra de fuste foi de $\mathrm{R} \$ 300,25 \mathrm{ha}^{-1}$.

\section{CONCLUSÕES}

A altura excessiva de corte por toco, mesmo em poucos centímetros, teve impacto nos volumes colhidos nos tocos e sortimentos $\left(8,49 \mathrm{~m}^{3} \mathrm{ha}^{-1}\right)$ e, consequentemente, na renda bruta a ser obtida, com perda financeira de $\mathrm{R} \$ \mathrm{ha}^{-1}$ $1.537,66$.

\section{REFERÊNCIAS}

ALVARES, C. A. et al. Köppen's climate classification map for Brazil. Meteorologische Zeitschrift, v. 22, n. 6, p.711-728, 2013.

ASSMANN, E. The principles of forest yield study. ed. New York: Pergamon Press, 1970. 506 p.

BRAMUCCI, M.; SEIXAS, F. Determinação e quantificação de fatores de influência sobre a produtividade de "harvesters" na colheita florestal. Scientia Forestalis, n. 62, p. 62-74, 2002.
CAMPOS, C.; TAVARES, M. Influência do comprimento e origem do toro na optimização do aproveitamento e do valor de rolos de pinho bravo. Silva Lusitana, v.18, n.1, p.123-132, 2010.

EMBRAPA. Empresa Brasileira de Pesquisa Agropecuária. Sistema brasileiro de classificação de solos. 3. ed. Brasília: Embrapa, 2013. 353 p.

FERREIRA, O. O. et al. Avaliação das perdas de colheita de madeira em floresta comercial/industrial. Ciência Florestal, Santa Maria, v. 5, n. 1, p. 129-137, 1995.

FIEDLER, N. C et al. Análise da qualidade da colheita florestal de eucalipto em diferentes declividades. Revista Científica Eletrônica de Engenharia Florestal, v. 22, n. 1, p. 1-8, 2013.

LEITE, E. D. S. et al. Análise técnica e de custos do corte florestal semimecanizado em povoamentos de eucalipto em diferentes espaçamentos. Cerne, v. 20, n.3, p. 637-643, 2014.

LIMA, J. S. S.; LEITE, A. M. P. Mecanização. In. MACHADO, C. C. (Ed). Colheita florestal. 2 ed. Viçosa: UFV, 2014. Cap.2, p.46-73.

LOPES, E. D. S. et al. Avaliação do treinamento de operadores de harvester com uso de simulador de realidade virtual. Revista Árvore, v. 32, n. 2, p. 291-298, 2008.

MACHADO, C. C. Colheita florestal. 3. ed. Viçosa: Ed. UFV, 2014.

MALINOVSKI, J. R.; CAMARGO, C. M. S.; MALINOVSKI, R. A.; MALINOVSKI, R. A.; CASTRO, G. P. Sistemas. In: MACHADO, C. C. Colheita florestal. 3. ed. Viçosa: UFV, 2014. Cap 6, p. 178-205.

NANVONAMUQUITXO, S. J. A. et al. Desperdício de madeira na concessão florestal da indústria Sotomane na província da Zambézia, Moçambique. Nativa, v. 5, n. 3, p. 208-211, 2017.

$R$ CORE TEAM. R: A language and environment for statistical computing. Vienna: $R$ Foundation for Statistical Computing. Disponível em: <https://www.R-project.org/>. Acesso em 16/05/2018.

REBOLETO, I. et al. Análise da qualidade do corte semimecanizado de eucalipto em diferentes declividades. Revista Agropecuária Científica no Semiárido, v. 12, n. 3, p. 268-272, 2016.

SERPE, E. L. et al. Perdas volumétricas relativas à colheita florestal e seus reflexos econômicos. BIOFIX Scientific Journal, v. 3, n. 1, p. 172-176, 2018a.

SILVA, E. P. et al. Fatores organizacionais e psicossociais associados ao risco de LER/DORT em operadores de máquinas de colheita florestal. Revista Árvore, v. 37, n. 5, p. 889-895, 2013.

SIMÕES, D.; FENNER, P. T. Influência do relevo na produtividade e custos do harvester. Scientia Forestalis, v. 85, n. 38, p. 107-114, 2010.

STROHER, R. R. et al. Avaliação da perda de madeira em dois sistemas de colheita florestal mecanizada. Enciclopédia Biosfera, v. 10, n. 19, p. $238-249,2014$ 